\title{
Springboard - a course aimed to address clinical and non-clinical concerns of physicians returning to practice
}

\author{
Authors: Claire Mullender, ${ }^{\mathrm{A}}$ Emily Gowland, ${ }^{\mathrm{A}}$ Charlotte Ford, ${ }^{\mathrm{A}}$ Marie Mcnulty, ${ }^{\mathrm{A}}$ Catherine Bryant, ${ }^{\mathrm{A}}$ Karen Le Ball, ${ }^{\mathrm{A}}$ \\ Andrew Deaner ${ }^{A}$ and Jonathan Birns ${ }^{A}$
}

\begin{abstract}
Introduction
A high proportion of physicians in London take time out of training for a number of reasons, including parental leave, health-related absence and approved learning opportunities in research, education and leadership. While out of programme, trainees may feel a loss of momentum with regard to career progression and/or a sense of professional isolation. On returning to practice, trainees may feel 'out of touch' with advances in practice and clinical developments which may, in turn, lead to a perceived lack of competence in what may be 'dormant' generic and specialty knowledge and skills.
\end{abstract}

\section{Methods}

A team of trainers and trainees at the London School of Medicine, Health Education England established a course, named Springboard, to support doctors in training taking career breaks to optimise management of their absence and subsequent return to practice. Using a 'plan, do, study, act' mode of quality improvement over a 5-year period, the course was developed to take place over 2 consecutive days and consist of clinical update seminars, clinical skills workshops, practical procedure simulation sessions, expert panel discussions, peer-led practical advice/professional support sessions and provision of 'return to practice' and 'clinical update' guides. Course attendees completed validated pre- and postcourse questionnaires containing both quantitative questions, based on a Likert rating scale (0-5), and open-ended qualitative questions pertaining to the benefits of the course. A mixed method evaluation approach was used to evaluate questionnaire data.

\section{Results}

A total of 540 trainees attended Springboard between 2014 and $2019,65 \%$ of whom (351) completed questionnaires. $79 \%$ of attendees were ST3-ST7 trainees, $8 \%$ were core medical trainees and the remainder were clinical fellows, GP trainees or staff grade doctors. Quantitative analysis of pre- and post-course responses showed that, by attending Springboard, there was a significant increase in participants' median [IQR] scores of self-reported leadership skills (3 [2] vs 4 [1]; $p<0.0001$ ) and confidence in being prepared to return to practice ( 3 [3] vs 4 [1]; $p<0.0001$ ), manage a cardiac arrest ( 3 [2] vs 4 [1]; $p<0.0001$ ) and run the acute medical take (3 [2] vs 4 [1]; $p<0.0001$ ). Qualitative analysis demonstrated four major themes of trainees considering an improvement of their confidence by attending the course and an appreciation of practical sessions, new updates/clinical guidance and the experience of meeting other physicians returning to practice. The most highly rated clinical updates and workshops pertained to 'stroke mimics', 'gastroenterology updates', 'ECG interpretation' and 'advanced life support'.

\section{Conclusions}

Springboard is a conference tailored to the needs of physicians returning to practice that was demonstrated to provide an opportunity for improving confidence relating to many areas of clinical and non-clinical practice, as well as providing an environment for networking and sharing experiences. Such an evaluation may be utilised for future collaboration with other specialties and disciplines.

\section{Conflicts of interest}

None declared. 